\title{
Application of Some Polymer Latexes in Preventing Paper Documents Forgery
}

\author{
Mohamed B. Gazy ${ }^{1}$, Waleed K. El-Zawawy², Alaa E. Elsayed ${ }^{3}$, Taha M. A. \\ Eldebss $^{4}$, Mohamed R. Helal ${ }^{5}$, Khaled E. Rashed ${ }^{\text {** }}$ \\ ${ }^{1}$ Chemistry Department, Faculty of Science, Al-Azhar University, Cairo, Egypt. \\ ${ }^{2}$ Cellulose and paper Department, National Research Center, Giza, Egypt. \\ ${ }^{3}$ Polymers and Pigments Department, National Research Center, Giza, Egypt. \\ ${ }^{4}$ Chemistry Department, Faculty of Science, Cairo University, Giza, Egypt. \\ ${ }^{5}$ Forensic Medicine Authority, Ministry of Justice, Cairo, Egypt.
}

\begin{abstract}
$\mathbf{T}$ HE MAIN objective of this research is to improve ink printability of papers via their modification with various types of water-based polymer latexes during paper manufacturing process. In order to achieve this target, various types of styrene-acrylate polymer latexes were used for modification of different types of papers. Styrene-acrylate latexes were prepared via emulsion polymerization of styrene with various acrylate monomers using emulsion polymerization technique. The effect of different emulsifying agents on the properties of the prepared emulsions was studied. The obtained results showed a significant improvement in degree of gloss and ink density on the polymer-coated papers which positively affect the ink ability, and ink holding properties of the modified paper. In addition, ink gloss and ink density of the coated papers improved with increasing the concentration of modifying latexes containing Texapon ${ }^{\circledR P}$ as emulsifier. These promising results open the way to use polymer latexes in treatment of documented value which can be used in stabilization of disappearing ink on paper leading to prevent forgery.
\end{abstract}

Keywords: Coated paper, Forgery, Erasable ink, Disappearing ink, Polymer latex, Physicochemical properties.

\section{Introduction}

In recent years, the development of ink industry led to the emergence of new types of inks that have wide applications in editing and writing on paper and other printable materials. Erasable and disappearing inks are popular examples of these new inks. These inks have wide applications and different uses in our life. For example, erasable ink pens (easily removed by a rubber eraser) are made primarily for children and school pupils in the early stages to minimize writing mistakes due to large number of errors that occur during the writing. On the other side, disappearing inks (their colors disappear upon exposure to air) are made to be used in textile industry, such as dressmaking crafts. In addition, it is used as kind of teaching materials, where the question is printed as the visible part and the spaces for answers are printed by disappearing ink pens as the invisible part. The answers only become visible when we use a coloring assistant that shows the ink color again [1].
Disappearing inks are water-soluble (acidbase) indicators that change its color (or color disappearance) upon exposure to air depending on the preservation methods and $\mathrm{pH}$ of the medium. Unlike disappearing inks, erasable inks are not penetrated into the microfibers of paper document and form a dry ink film on the surface of paper.

In the crime world, unfortunately, these properties of erasable and disappearing inks have been exploited in an unethical way in forgery or counterfeiting crimes. Some people used these pens (erasable inks or inks that can disappear after a period of time) to write documents in bad faith and exploit them in manipulation, fraud and forgery. This is done by removing this writing (in case of erasable ink) using a rubber eraser, or by leaving that document for a period of time until the color of the ink completely fades or disappear (in case of disappearing ink) and therefore cannot be seen with the naked eye.

*Corresponding author e-mail: khaledrashed178@yahoo.com 
In forensic science, Document validation is an important issue which helps to detect whether or not a document is forged. In this context, there are different ways and levels of detection of counterfeit documents, depending on the validation features to be examined and the used type of ink [2]. Therefore, to overcome many of the problems resulting from using of these inks in document forgery, it is necessary to enact new laws to limit the use of these inks to write the documents value. On the other hand, research is underway in full swing to reduce this phenomenon using certain types of papers which difficult to falsify using these types of inks. This goal can be achieved by processing or modifying valuable papers during the manufacturing processes using certain types of polymers (acrylate latexes) that help to hold the ink on the surface of the paper for as long as possible even using these types of inks, and thus difficult to forge [3].

Paper documents are mainly composed of cellulosic materials (i.e. natural polymers) which are widely produced worldwide. During the paper processing, various treating additives (e.g. fillers) and finishing agents (e.g. polymers) are used to enhance surface features of paper, including appearance, mechanical properties, gloss, smoothness, etc, in addition to printing properties. The appearance is clearly different between polymer-coated and uncoated papers. Both optical features and quality of paper are upgraded by filling cavities, covering fibers and consequently, smoothening paper superficially $[4,5]$.

The fundamental purpose of coating by using latex formed by emulsion polymerization reaction is to add-on paper or board surface quality. To achieve this criterion, many properties are considered to be improved such as brightness; gloss or opacity [optical properties]; smoothness [tactile properties]; print gloss and density [printability] and print image quality [6]. And Coating can be made up of pigments, binders, thickeners and various additives. The most vital component of coating is the binder "latex". The binder, usually a combination of binders, could join pigment particles to base paper (substrate) and unite them to each other.

Generally, the surfactants act in two ways during emulsion polymerization. Surfactants give rise to micelle formation where polymerization takes place and they also stabilize the emulsion polymer from coagulation.

A critical issue in commercial latex manufacture is their stability during and after production. The surfactants have an effect on overall emulsion stability. Thus, the appropriate surfactant selection is an important consideration when designing a formulation.

Anionic surfactants such as Sodiumlauryl ether sulfate (SLS), Texapon P and nonionic such as Ethoxylated Nonyl Phenol "NP30", Cetylalcohol emulsifiers are the most effective and widely used surfactants in emulsion polymerization. While anionic surfactants (prevent coagulation due to electrostatic repulsions, nonionic ones prevent coagulation due to satiric stabilization $[7,8]$.

The objective of this research is to improve the properties of the paper surface by treating it with polymer emulsions, namely poly(butylacrylateco-styrene) emulsion, in order to enhance the fixation of various types of inks (physically or chemically) on the surface of paper used in counterfeiting. Consequently, this may prevent

TABLE 1. Formulation of disappearing inks.

\begin{tabular}{|c|c|c|}
\hline 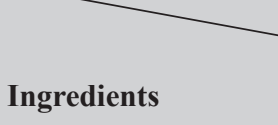 & $\mathbf{D}_{\mathrm{P}}$ & $\mathbf{D}_{\mathrm{T}}$ \\
\hline Phenolphthalein (g) & 0.75 & ---- \\
\hline Thymolphthalein (g) & ---- & 0.25 \\
\hline Ethanol (mL) & 10 & 10 \\
\hline $\mathrm{NaOH}(0.1 \mathrm{M})(\mathrm{mL})$ & 10 & 10 \\
\hline Glycerol (mL) & 6 & 6 \\
\hline $\mathrm{TiO}_{2}(\mathrm{~g})$ & 0.1 & 0.1 \\
\hline Distilled water $(\mathrm{mL})$ & 73.15 & 73.65 \\
\hline
\end{tabular}

Egypt. J. Chem. 62, No. 1 (2019) 
or reduce the possibility of removing or missing this ink after editing the document value and then limit forgery of documents.

\section{Materials and Methods}

\section{Inks and chemicals}

Solid and colorless acid-base indicators, namely phenolphthalein and thymolphthalein were used as the source of color of disappearing inks (disappearing inks used phenolphthalein Dp - disappearing inks used thymolphthalein DT). They were purchased from Alpha Chemica, Mumbai, India. Other reagents such as glycerol (C3H8O3, Sigma-Aldrich), ethanol (C2H6O, Sigma-Aldrich), sodium hydroxide $(\mathrm{NaOH}$, ADWIC for Chemicals, Egypt), and Titanium dioxide (TiO2 Euromedex France) were also used

TABLE 2. Papers sample with different brand names for preparation of disappearing ink formulations according to El-Molla et al [9[. The formulations of disappearing inks are represented in Table 1. Here it is worth to mention that thymolphthalein and phenolphthalein are colorless powders and convert to blue and red colors in alkaline solution, respectively.

On the other hand, ball point pens containing blue colored erasable inks (with a small eraser incorporated within the pen) were used. It is made in Japan under the trade name "Frixion".

For preparation of erasable ink formulation, 1 gram of ink from the ball point pens was extracted and dissolved in $100 \mathrm{~mL}$ distilled water. Then, the obtained ink solution was applied on different types of paper documents.

\begin{tabular}{l|c}
\hline \multicolumn{1}{c}{ Paper brand } & Code of paper \\
\hline Rakta & P1 \\
\hline Quena & P2 \\
\hline Edfu & P3 \\
Trust receipts with white background & P4 \\
\hline Trust receipts with blue background & P5 \\
\hline Handbook white paper & P6 \\
\hline
\end{tabular}

\section{Papers}

Different types of locally produced (commercial) papers sheets were used in this study. These paper sheets were kindly delivered from Rakta, Quena and Edfu Paper Mill Companies and some other papers were purchased from Egyptian market as follows:

- Local writing-photocopy and printing white paper ( $80 \mathrm{~g}$ ) made of $80 \%$ rice straw bleached Kraft pulp, 15\% bleached softwood pulp and $5 \%$ calcium carbonate, locally produced at Rakta mill, Alexandria, Egypt.

- Local writing-photocopy and printing white paper (80 g) which is made of $80 \%$ bleached bagasse Kraft pulp,15\%bleached soft wood and $5 \%$ calcium carbonate, which is produced

TABLE 3. Polymerization recipe for preparation of poly (styrene-co-butylacrylate) latexes by emulsion polymerization containing different emulsifying agents.

\begin{tabular}{|c|c|c|c|c|c|}
\hline Ingredients & F1 & F2 & F3 & F4 & F5 \\
\hline St (g) & 50 & 50 & 50 & 50 & 50 \\
\hline $\mathrm{BuA}(\mathrm{g})$ & 50 & 50 & 50 & 50 & 50 \\
\hline $\mathrm{AA}(\mathrm{g})$ & 4 & 4 & 4 & 4 & 4 \\
\hline SLS (g) & 1.6 & 1.8 & 2.2 & - & - \\
\hline $\mathrm{NP}_{30}(\mathrm{~g})$ & 0.4 & 0.4 & 0.4 & 0.4 & - \\
\hline Texapon $^{\circledR} \mathrm{P}(\mathrm{g})$ & - & - & - & 1.6 & 2.2 \\
\hline Cetyl alcohol (g) & - & - & - & - & 0.4 \\
\hline KPS (g) & 0.75 & 0.75 & 0.75 & 0.75 & 0.75 \\
\hline Sodium acetate (g) & 0.6 & 0.6 & 0.6 & 0.6 & 0.6 \\
\hline
\end{tabular}


by the Egyptian Sugar and Integrated Industries Company, Quena, Egypt.

- Local writing-photocopy and printing white paper $(80 \mathrm{~g})$ which is made of $70 \%$ bleached bagasse Kraft pulp,25\% bleached softwood, and $5 \%$ calcium carbonate, which is produced by the Egyptian Sugar and Integrated Industries Company, Edfu, Egypt.

- Trust receipts with a white background, locally produced by laser printing.

- Trust receipts, with a blue background, locally produced by laser printing.

- Handbook white papers for writing.

Ten sheets from each of paper were used with the same batch to avoid substrate variability. Table 2 represents the type of papers used in this study.

\section{Polymer latexes}

Previously prepared polymer latexes based on poly (styrene-co-butylacrylate) emulsions [10] were used for paper coating. Briefly, Styrene (St), butyl acrylate (Bu A), and acrylic acid (AA) monomers were copolymerized using emulsion polymerization at $80 \mathrm{oC}$ in presence of potassium per sulfate (KPS) initiator for $24 \mathrm{hrs}$ under inert Nitrogen atmosphere and continuous stirring. The effect of different emulsifying agents on the properties of the prepared emulsions was studied. These emulsifying agents include sodium auryl ether sulfate (SLS), Texapon®P, Ethoxylated Nonyl Phenol "NP30", and Cetylalcohol. Sodium acetate and ammonium hydroxide were used as buffers and for $\mathrm{pH}$ control agents, respectively (Table 3).

Table 3 shows the combination of different surfactants used for styrene-acryl ate copolymer preparation. The latex containing fixed monomer ratio of styrene and butyl acryl ate 50/50 weight percentage were prepared at different ratio of emulsifier using sodium lauryl ether sulfate (SLS) and ethylated nonyl phenol NP30. (F1 to F5) are Polymer latex formulation.

Characterization of paper surface coated with polymer latex

Ten Paper strips of $30 \mathrm{~mm}$ length and 10 $\mathrm{mm}$ width were prepared according to ISO 28341(2006) [11]. Samples of each paper type were used for treatment with the prepared polymer latexes. The treatment process was carried out by soaking paper samples in the prepared polymer latexes at different polymer concentrations.

\section{Thickness}

Thickness of coated papers was measured by Lorentzen Zwettre apparatus, made in Sweden, according to TAPPI standard (TAPPI $\mathrm{T} 410$ ) while basis and coated weights were measured by laboratory digital balance with an accuracy of $1 \mathrm{mg}$.

\section{Ink printing process}

Polymer-coated paper strips were treated with different types of inks, including erasable ink (E), disappearing inks based on phenolphthalein (DP) and thymolphthalein (DT). A sufficient amount of each ink from different concentrations was charged into the IGT printing machine and distributed uniformly on different rolls of the inking unit. The printing disc was cleaned after printing of each paper strip using an organic solvent (cyclohexanone). For each type of paper sheets, a series of strips was printed with the same ink. Then, printed papers were allowed to air-dry overnight.

\section{Ink Gloss and Ink density measurements}

Ink gloss and ink density were calculated by measuring various reflectance values on the test strips.

Ink Gloss describes the mirror-like property of inked surface and defined as the percentage of light reflected from the surface at an angle equal to the angle of incidence, in comparison with a standard surface. Ink gloss was measured by micro gloss meter, at $75^{\circ}$ angle. The test was performed according to standard TAPPI T 480, Om -92 [12].

Ink density "ID" is the optical contrast between the inked and uninked areas on the paper surface. This contrast is usually determined from the measurement of reflectance values of inked and uninked areas as follows:

$$
\mathrm{ID}=\log \left(\mathrm{R} \infty / \mathrm{R}_{\mathrm{p}}\right)
$$

Where $\mathrm{R}_{\infty}$ is reflectance of uninked paper, and $\mathrm{R}_{\mathrm{p}}$ is reflectance of the inked paper, respectively.

The reflectance measurements were carried out by a Spectroeye apparatus, X-rite Company, made in USA. Averages of five measurements were recorded for each inked strip.

\section{Scanning electron microscopy (SEM)}

Morphology and microstructure of paper samples (coated and uncoated) can be investigated using scanning electron microscopy (SEM). 
Samples were dried at $100 \mathrm{oC}$ for an hour. SEM Quanta FEG 250, made in Japan was used for studying the morphology of the coated paper samples.

\section{Photomacrography}

Stability of each printed ink (at different concentrations) on polymer-coated papers and on uncoated papers (as a blank) was compared visually. The used inks are erasable ink (E), and phenolphthalein (DP) and thymolphthalein (DT) disappearing inks, and the control (blank) sample (uncoated papers). Different photos were taken for each type of ink using a camera Model: Sony DECWX220, HDMI, 18.2 mega pixels, VCHD, Optical zoom $10 \times$, Syber-Shot, Made in China.

\section{Results and Discussion}

The amount of polymer latex used for paper coating has a great influence on the physical and optical surface properties of paper. Thus, the following paper parameters were taken into consideration including: basis weight of uncoated paper, weight of coated paper and thickness to observe the physical change of coated papers compared to blank ones.

Physical properties of the prepared styreneacrylate polymer latexes were determined in terms of their solid content, particle size, colloidal stability, and molecular weight as indicated in Table 4.

From the following table, Zeta potential for all polymer latex particles possesses negative charge with higher values which indicate the outstanding colloidal stability of all prepared latexes. The values of poly dispersive index (PDI) lies between
0.73 and 1.44. Proves that the Polymer latex formulation has the highest colloidal stability.

\section{Physical properties of polymer-coated papers \\ Basis weight and thickness measurements}

Basis weight and thickness measurements are the basic physical changes when applying a coating on the paper surface Table 5. Coating layer makes paper thicker than the original sample and changes physically the basis weight of paper. In addition, coating weight depends mainly on the type and ratio of polymer latex. The higher porosity paper of surface allows the polymer coating to penetrate into the paper sheet and increases the coat weight needed to cover the paper surface [13]. Tables 5 represent the characterization of basis weight and thickness of different types of paper coated with various prepared polymer latex emulsions (F1, F2, F3, F4 and F5, respectively).

The coating polymer film forms a continuous layer on the surface of the paper and fills also the internal pores in the paper surface. Morsy and ElSherbiny, [14] studied the influence of coating properties and pigment blends on mechanical properties of coated paper. They found that the tensile strength was improved when solid content (wt $\%$ ) and coating film thickness of the binder were increased. Forsstrom et al. [15] reported that the highest coat weights are obtained on porous papers. Neither paper roughness nor surface chemistry in the studied area had any effect on coat weight formation. Low paper surface porosity and/or high filler content on the surface of the transparent paper decreases coating color penetration into the paper structure and the coating color stays on the paper surface. On the other hand, Kentta et al. [16] reported that the uniformity of paper surface improved as the coat weight increased.

TABLE 4. Characterization of (Styrene-co-butylacrylate) copolymer emulsions.

\begin{tabular}{|c|c|c|c|c|c|c|}
\hline \multicolumn{2}{|c|}{ Physical parameter } & F1 & F2 & F3 & F4 & F5 \\
\hline \multicolumn{2}{|l|}{ Solid content (\%) } & 46.6 & 45.9 & 44.9 & 47.8 & 49.9 \\
\hline \multicolumn{2}{|l|}{ Particle size (nm) } & 143 & 140 & 145 & 129 & 120 \\
\hline \multicolumn{2}{|l|}{ Zeta potential (mV) } & -30 & -37 & -30 & -37 & -48 \\
\hline \multirow{2}{*}{ Molecular weight } & $\mathrm{M}_{\mathrm{w}} * 10^{5}(\mathrm{~g} / \mathrm{mol})$ & 2.2 & 2.5 & 2.7 & 1.3 & 5.9 \\
\hline & $\mathrm{M}_{\mathrm{n}} * 10^{4}(\mathrm{~g} / \mathrm{mol})$ & 2 & 2.5 & 3.7 & 0.9 & 5.2 \\
\hline PDI & & 1.1 & 1.0 & 0.73 & 1.44 & 1.13 \\
\hline
\end{tabular}


TABLE 5. Basis, coat weight and thickness of coated paper.

\begin{tabular}{|c|c|c|c|c|c|c|}
\hline & \multicolumn{6}{|c|}{ F1 } \\
\hline Paper samples & P1 & $\mathbf{P 2}$ & P3 & P4 & P5 & P6 \\
\hline Basis weight $\left(\mathrm{g} / \mathrm{m}^{2}\right)$ & 85.0 & 85.3 & 85.0 & 85.5 & 85.0 & 83.0 \\
\hline Coat weight $\left(\mathrm{g} / \mathrm{m}^{2}\right)$ & 1.7 & 2.7 & 1.5 & 2.0 & 2.0 & 3.0 \\
\hline Thickness $(\mu \mathrm{m})$ & 111 & 113 & 103 & 101 & 93 & 97 \\
\hline Formula & \multicolumn{6}{|c|}{ F2 } \\
\hline Basis weight $\left(\mathrm{g} / \mathrm{m}^{2}\right)$ & 84.0 & 84.3 & 85.0 & 86.5 & 86.0 & 83.0 \\
\hline Coat weight $\left(\mathrm{g} / \mathrm{m}^{2}\right)$ & 0.7 & 1.3 & 1.0 & 3.5 & 3.0 & 3.0 \\
\hline Thickness $(\mu \mathrm{m})$ & 110 & 112 & 103 & 103 & 94 & 96 \\
\hline Formula & \multicolumn{6}{|c|}{ F3 } \\
\hline Basis weight $\left(\mathrm{g} / \mathrm{m}^{2}\right)$ & 86.0 & 85.3 & 85.0 & 86.5 & 85.0 & 83.0 \\
\hline Coat weight $\left(\mathrm{g} / \mathrm{m}^{2}\right)$ & 2.7 & 2.3 & 2.0 & 3.0 & 2.0 & 3.0 \\
\hline Thickness $(\mu \mathrm{m})$ & 111 & 112 & 102 & 100 & 92 & 96 \\
\hline Formula & \multicolumn{6}{|c|}{ F4 } \\
\hline Basis weight $\left(\mathrm{g} / \mathrm{m}^{2}\right)$ & 84.0 & 84.3 & 87.0 & 84.5 & 84.0 & 83.0 \\
\hline Coat weight $\left(\mathrm{g} / \mathrm{m}^{2}\right)$ & 1.7 & 4.0 & 0.3 & 1.5 & 1.0 & 3.0 \\
\hline Thickness $(\mu \mathrm{m})$ & 112 & 112 & 102 & 100 & 91 & 96 \\
\hline Formula & \multicolumn{6}{|c|}{ F5 } \\
\hline Basis weight $\left(\mathrm{g} / \mathrm{m}^{2}\right)$ & 86.0 & 86.3 & 88.0 & 85.5 & 86.0 & 83.0 \\
\hline Coat weight $\left(\mathrm{g} / \mathrm{m}^{2}\right)$ & 2.7 & 4.5 & 3.3 & 2.5 & 3.0 & 3.0 \\
\hline Thickness $(\mu \mathrm{m})$ & 113 & 113 & 103 & 102 & 93 & 97 \\
\hline
\end{tabular}

Basis weight and thickness measurements are the basic physical changes when applying coating on paper surface due to:

- Coating layer makes paper thicker than the original one.

- Coating layer changes the basis weight of paper physically.

- Coating weight depends mainly on the type of pigment. A more open surface allows the coating to sink into the sheet and increases the coat weight amount needed to cover the surface.

The increase in basis weight and thickness of papers attributed to the quantity of coat required to occupy the valleys on the surface. In other words, a more open surface allows the coating sink into the sheet and thus; increasing the coat weight required to cover the surface [17].

Inking ability of polymer latex-coated paper "Evaluation of ink quality"

Ink ability is the tendency of ink to interact

Egypt. J. Chem. 62, No. 1 (2019) (physically and/or chemically) with paper surface and to penetrate into the paper microstructure [18]. Generally, the basic mechanism controlling ink behavior with paper surfaces is specifically penetration of the ink [19]. In order to enhance the interaction of ink with paper surface, the inking ability of polymer-coated papers was investigated in terms of ink gloss, ink density, and paper surface morphology using SEM.

The ink ability of paper is predominantly evaluated by the nature of the coating material and its chemical structure and topology distribution. At the same time, the polymer-coated paper must be porous enough to allow fast, controlled absorption of the ink and keeping the ink gloss intact. In general, the coated paper must have acceptable stiffness, resistance to blistering, good dimensional stability, high brightness, no or low yellowing tendency, and good aging resistance [5]

\section{Ink quality (ink gloss and density)}

Ink quality is expressed by sharpness of image, color, tone, gloss, ink density and the symmetry of these properties [20]. 
The size of polymer latex particles is very important in coating of paper the gloss of coated paper sheet is correlated with the fibers coverage caused by the polymer coating layer, and the roughness of coating. The latter has two most important components which unite to create the surface topography that influences gloss. One of them is the polymer particles give to the smallscale micro-roughness by asset of their size and shape, and the other the paper fibers lying below the coating affect the surface roughness, particularly at low coat weight, due to absence of complete appropriate between the small amount of polymer used in coating and size and shape of fibers [21].

The value of specular gloss is based on the surface structure and porosity of substrate, while the ink density depends on the thickness (i.e. amount) of ink on the paper surface, which reflects the stronger bonding between paper and ink [22].

Polymer-coated paper has two parts: the base paper and coating layer. Most base paper contains both chemical and mechanical, while, the coating layer contains particles of pigment binder. The uniformity and the thickness of coating layer greatly affect the ink gloss and quality. In addition, the interaction between ink and coating layer greatly affects the constancy and fastness of ink color for long periods.

As shown in Fig. 1 to 6, the ink gloss values of the polymer latexes with treated papers ( $\mathrm{P} 1$ to P6) were ranged between 8 and 35, while the ink density was ranged between 1.5 and 2.3.

It is clear from all types of investigated papers that the maximum ink gloss value 35 and ink

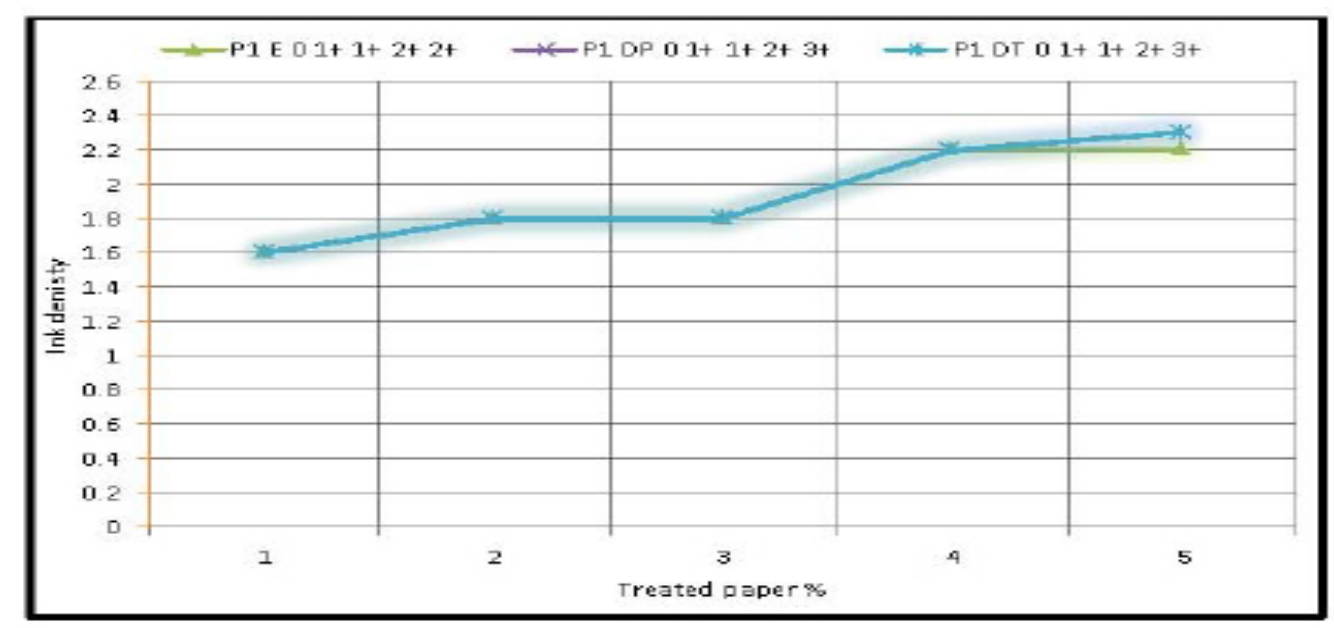

A

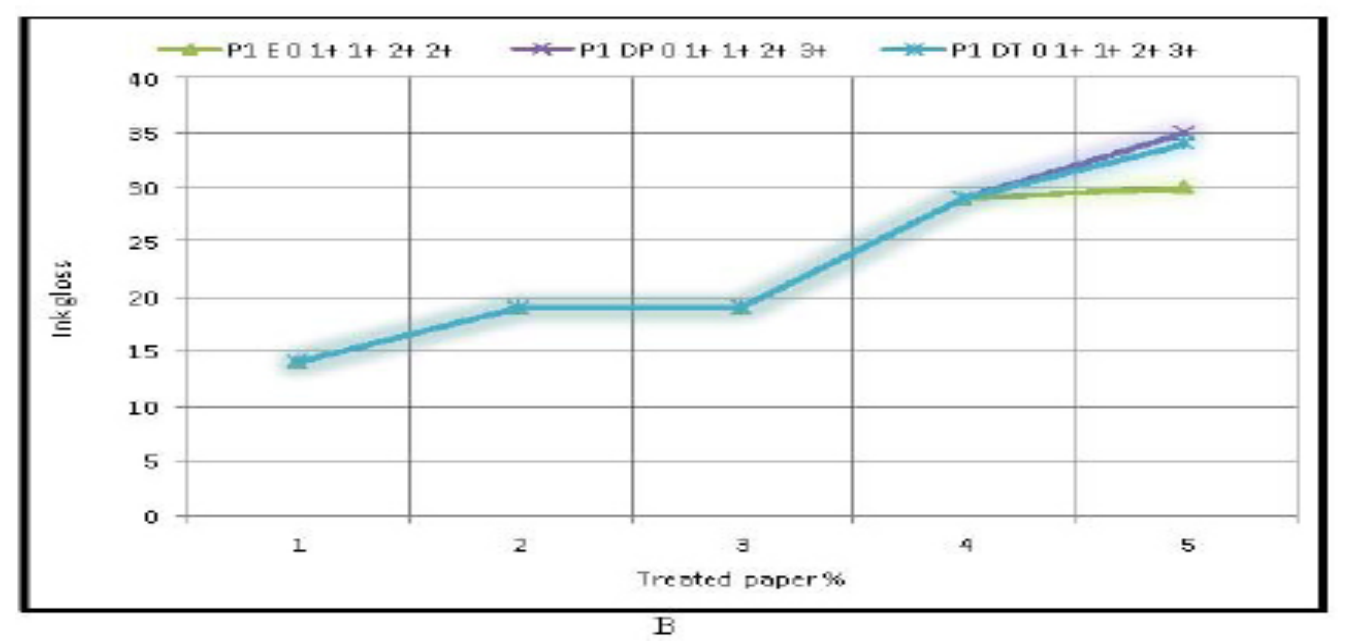

Fig. 1. Ink density (A) and ink gloss (B) of erasable and disappearing ink printed on Rakta coated paper with different concentrations of poly (styrene-co-butylacrylate) latexes (F5).

Egypt. J. Chem. 62, No. 1 (2019) 


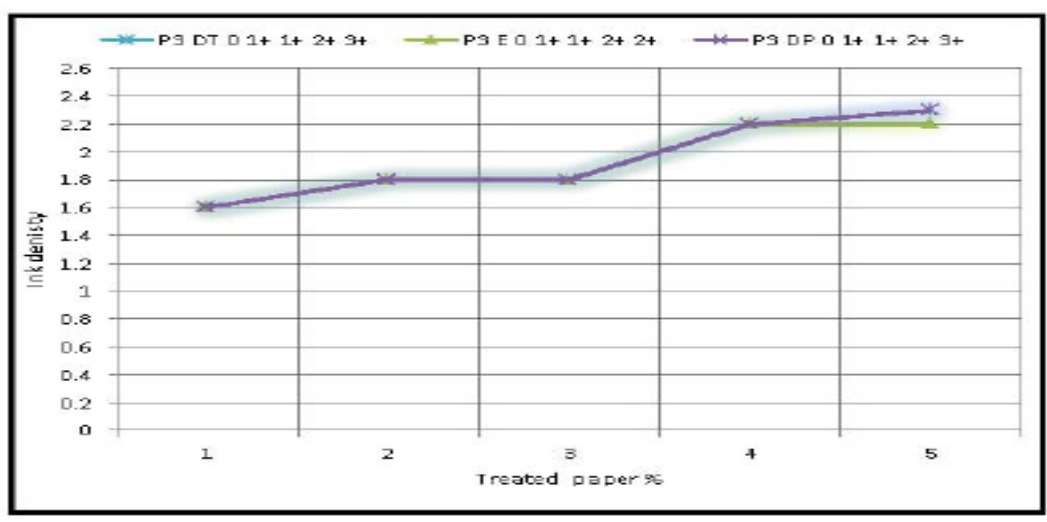

A

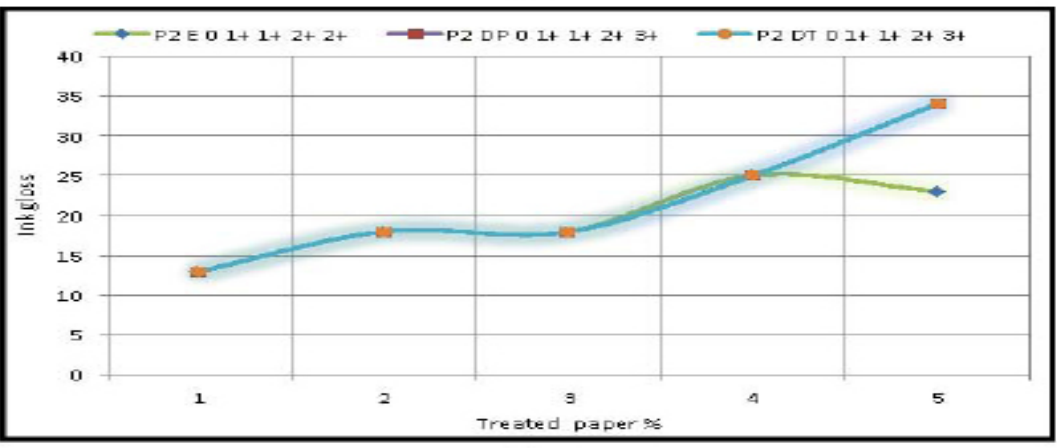

B

Fig. 2. Ink density (A) and ink gloss (B) of erasable and disappearing ink printed on Quena coated paper with different concentrations of poly (styrene-co-butylacrylate) latexes (F5).

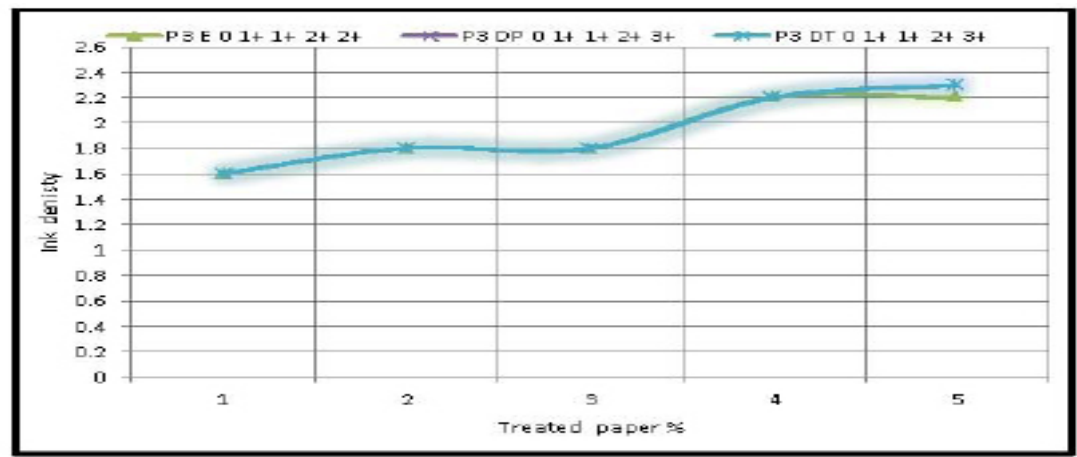

A.

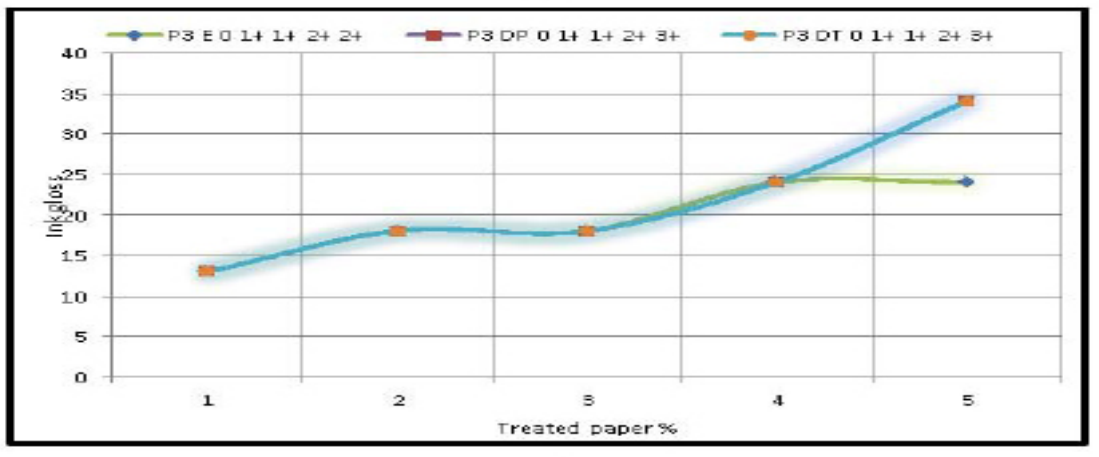

B

Fig. 3. Ink density (A) and ink gloss (B) of erasable and disappearing ink printed on Edfu coated paper with different concentrations of poly (styrene-co-butylacrylate) latexes (F5).

Egypt. J. Chem. 62, No. 1 (2019) 

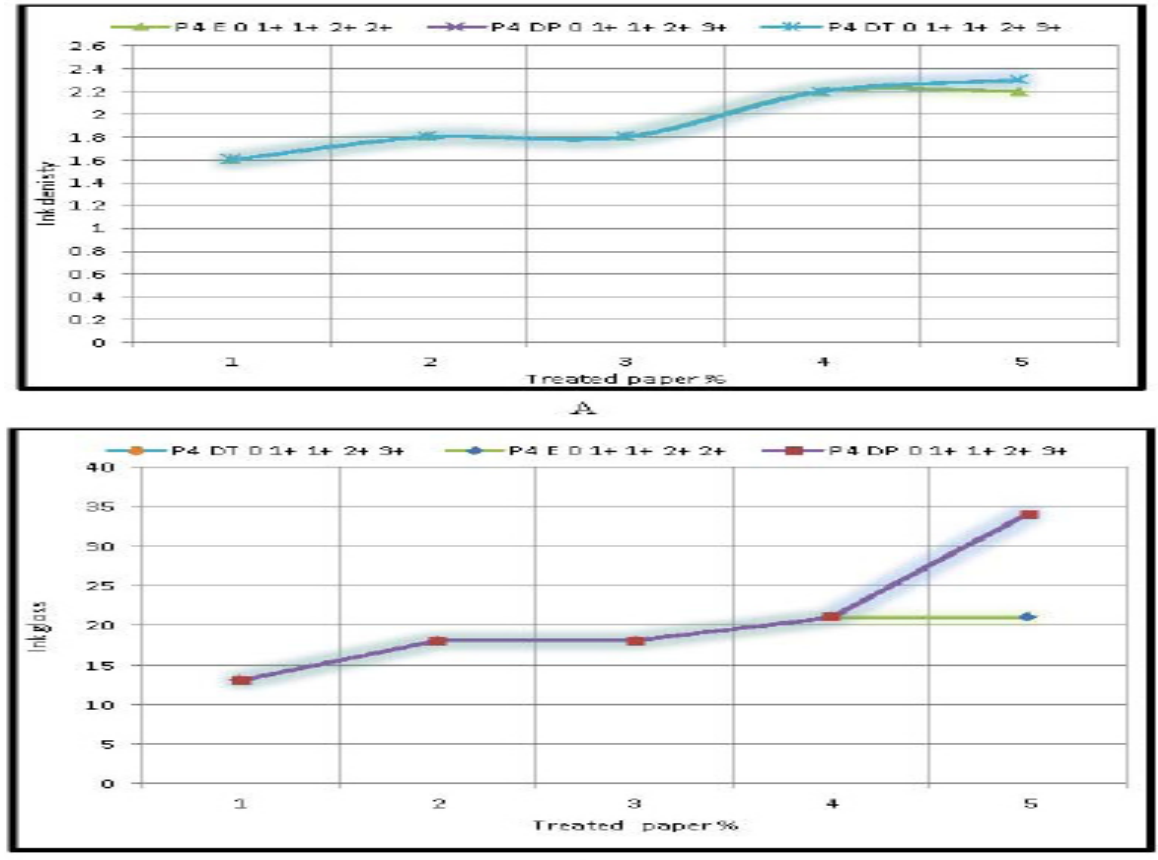

B

Fig. 4. Ink density (A) and ink gloss (B) of erasable and disappearing ink printed on Trust receipts with white background coated paper with different concentrations of poly (styrene-co-butylacrylate) latexes (F5).
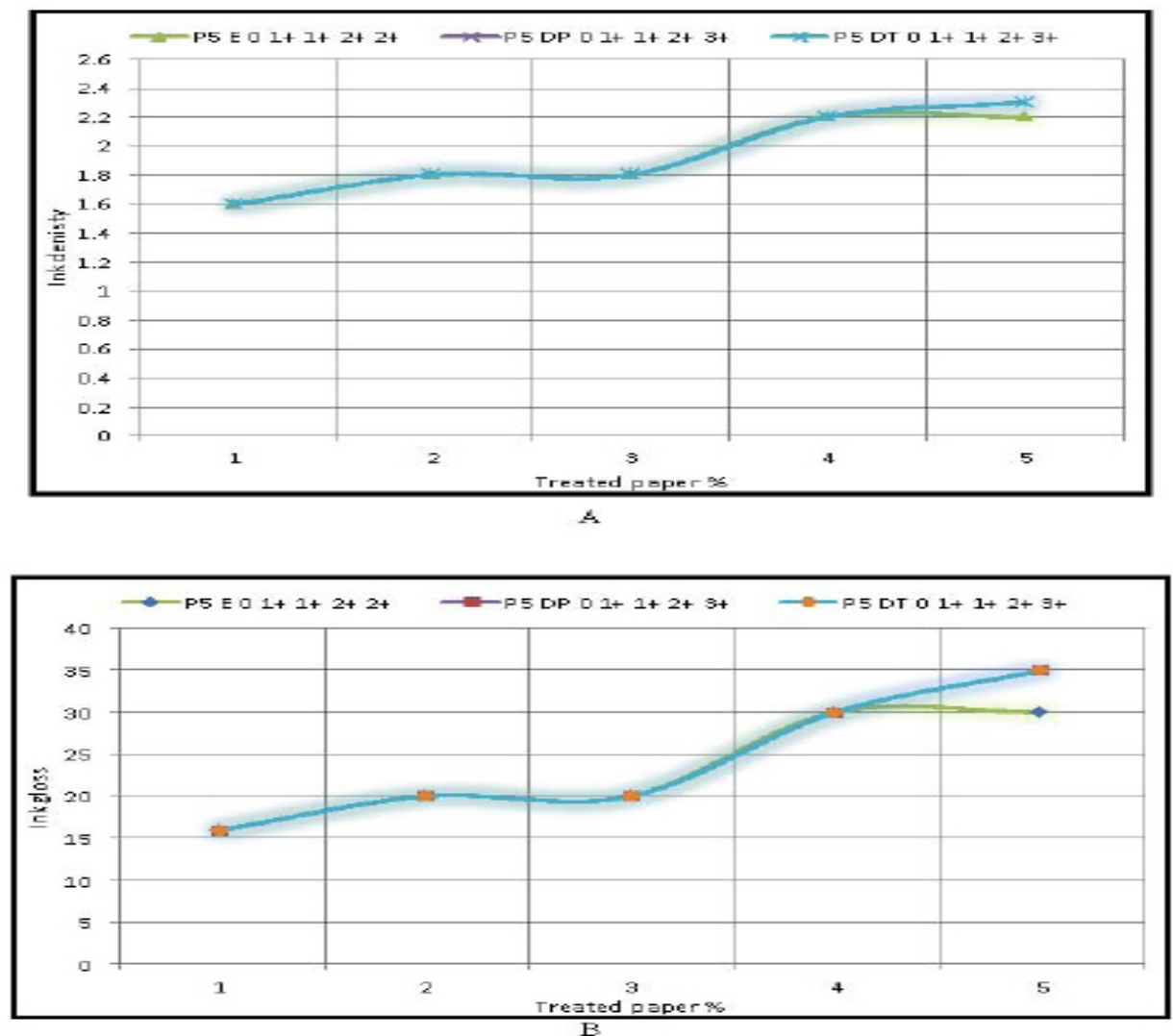

Fig. 5. Ink density (A) and ink gloss (B) of erasable and disappearing ink printed on Trust receipts with blue background coated paper with different concentrations of poly (styrene-co-butylacrylate) latexes (F5).

Egypt. J. Chem. 62, No. 1 (2019) 

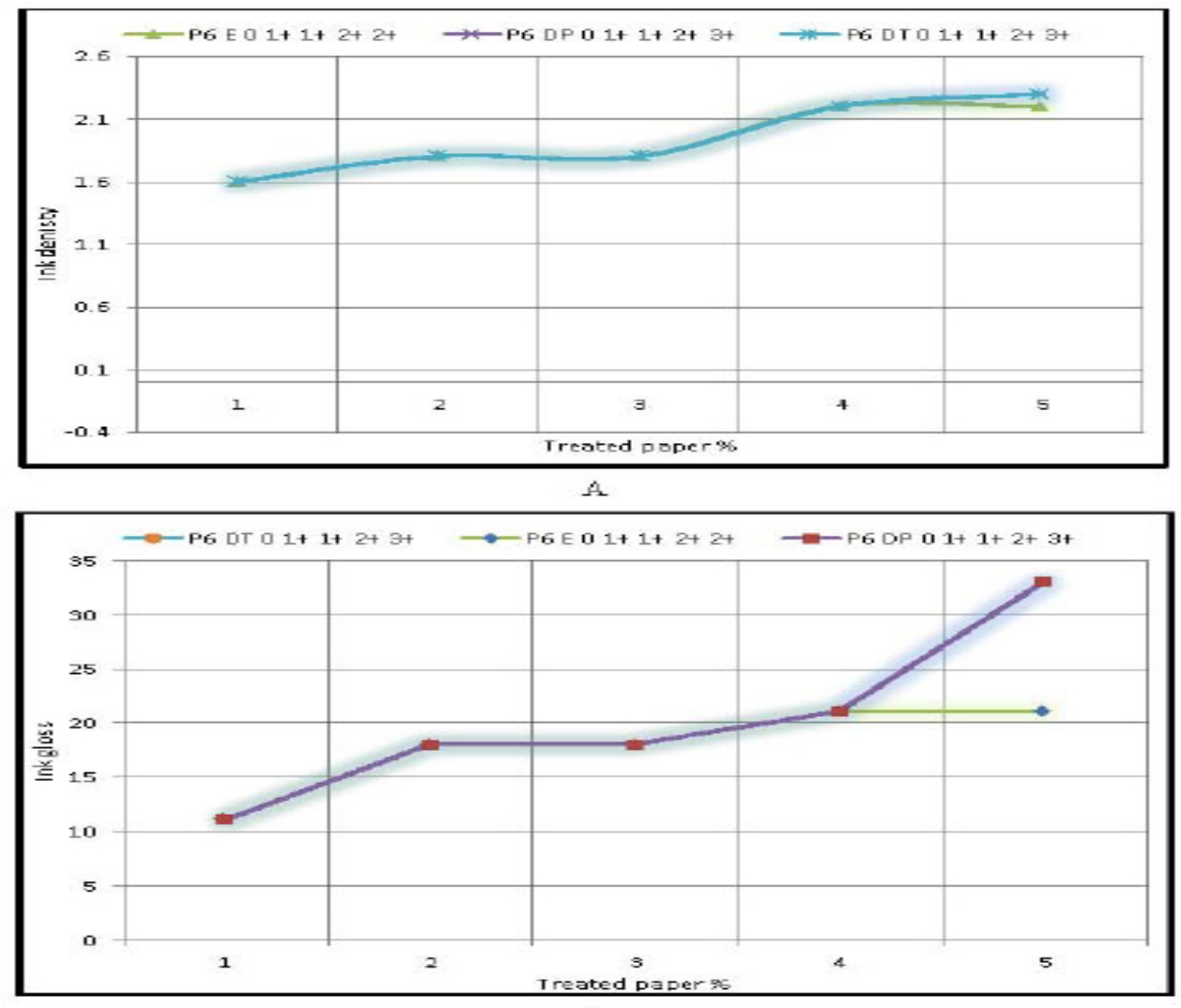

B

Fig. 6. Ink density (A) and ink gloss (B) of erasable and disappearing ink printed on Trust receipts with Handbook white paper coated paper with different concentrations of poly (styrene-co-butylacrylate) latexes (F5).

density value 2.3 were obtained for Quena paperscoated with poly (styrene-co-butylacrylate) latexes (F5) containing the anionic Texapon $\AA P$ and nonionic cetyl alcohol emulsifiers of $2 \mathrm{wt} \%$ concentration. The trend of ink gloss and ink density decreases in the following order: F5 $>$ F4 $>$ F3 $>$ F2 $>$ and then F1. This can be attributed to the high coated weight of polymer latex F5 indicating the increased amount of ink in the coated layer and therefore polymer 5 have the highest ink gloss.

The coated papers with poly (styrene-cobutylacrylate) latexes F5 containing Texapon ${ }^{\circledR} P$ and cetyl alcohol have high ink gloss and ink density values with disappearing ink whether contains phenolphthalein or thymolphthalein.

\section{Scanning electron microscopy (SEM) of coated and inked coated papers}

As the quality requirement on paper and ink are rising, better knowledge and understanding of the coating layer structure details and its interaction with inks are essential.

The ideal paper surface should be smooth with optional pore size to improve gloss and to keep a good interaction between the paper surface and the applied inks during inking process. Imperfections and irregularities on the paper surface structure should be eliminated.

Coated quena paper samples with $2 \%$ F5 formulation were inked with DP, DT and E inks using IGT printer. The coating layer components establish the layers, and thus the final properties of paper. The coating layers affect decisively the printing ink absorption [23, 24]. Ink can diffuse into the paper through pores by capillary action and gradually enter the paper surface. Figure 7 (A-C) shows the SEM of coated Quena paper.

The coating layer is composed of fillers having different shape and different particle size and produce different contrast in the obtained images [25].

Examination of paper surface by SEM (Fig.7), showed that the polymer coated the fiber of the paper beside the Ti element (used as tag for ink) present in disappearing ink, also (Fig. 7B and C] we find the polymer coated the fiber of the paper 
with ink, This means higher stability of ink on paper coat samples for inking purposes.

\section{Photomacrography}

Aggregation of ink on the coated paper is essential to prevent forgery processes. Degree of Aggregation of ink particles on the coated paper depends on the type of polymer used in coating process, these macrographs can elucidate the advanced ink density of these coated paper samples. Also, this type of binder shows good adhesion properties to pigment particles together [26].

Comparison of the coated papers with the control sample points to non-picking surface of all coated papers. The selection may be attributed to that the coating has reinforced adhesion of ink to the paper have polymer, [27, 28]. Figure 8 shows the photomicrographs of inked uncoated paper in which the color disappeared after 3 days and eras on using erasure while Fig. 9 shows high ink gloss and ink density for coated paper with polymer containing Texapon ${ }^{\circledR P}$ after about four months of coating.

\section{Conclusions}

In this research, polymeric latexes based on styrene-acrylate polymer latexes emulsion containing different surfactants were used for treatment of paper surface in order to improve the aesthetic appearance and ink ability of the paper documents. This in turn will lead to the fixation of ink on the surface of paper, particularly for those types of inks that can be erased or disappeared

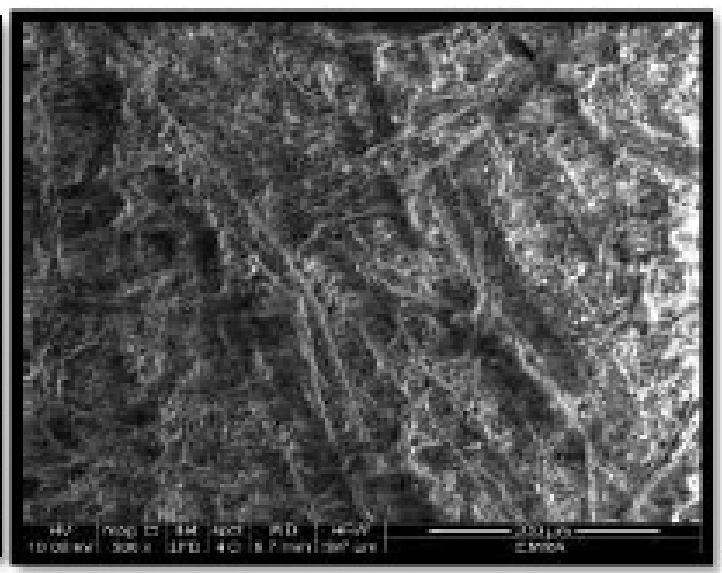

B

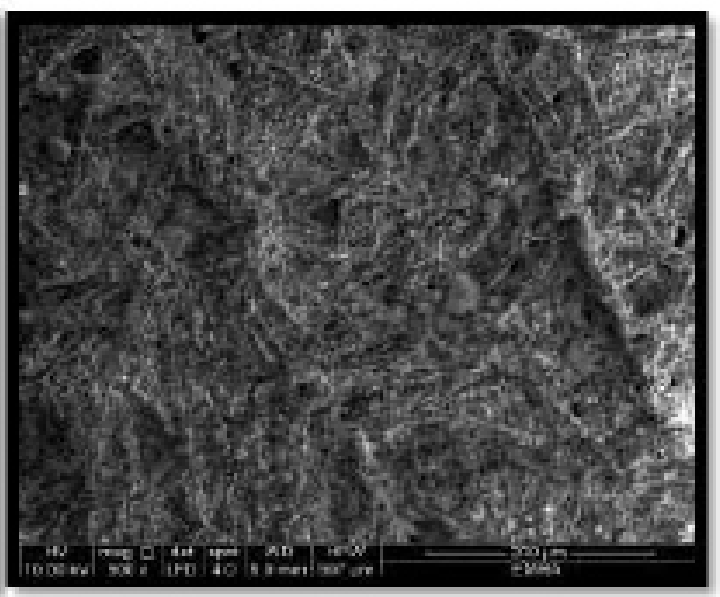

D

Fig. 7. SEM micrograph of coated Quena paper with poly (styrene-co-butylacrylate) latexes (F5) without ink (A), with DP ink (B), with DT (C) and with E ink (D). 
from the paper surface. Those types of inks can be used for forgery of documents value. The treatment of paper documents with specific polymer latexes during the processing and manufacturing of paper will lead to the improvement of ink interaction with paper surface then reduces or prevents the possibility of their forgery. In addition, polymeric latexes could develop smoothness, gloss, and mechanical properties of paper and final production cost.

The obtained results showed the significant

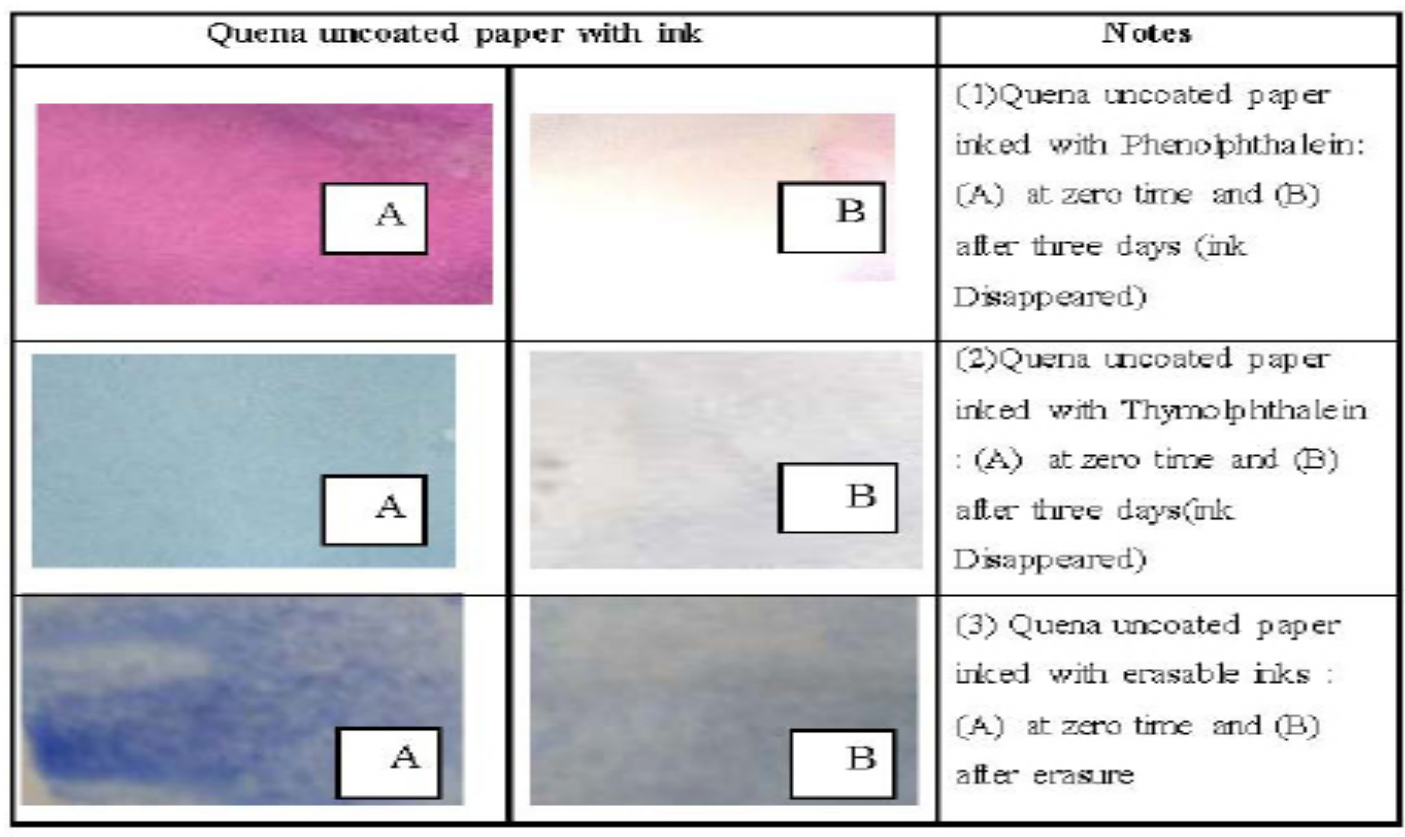

Fig 8. Photomicrographs of inked uncoated Quena paper

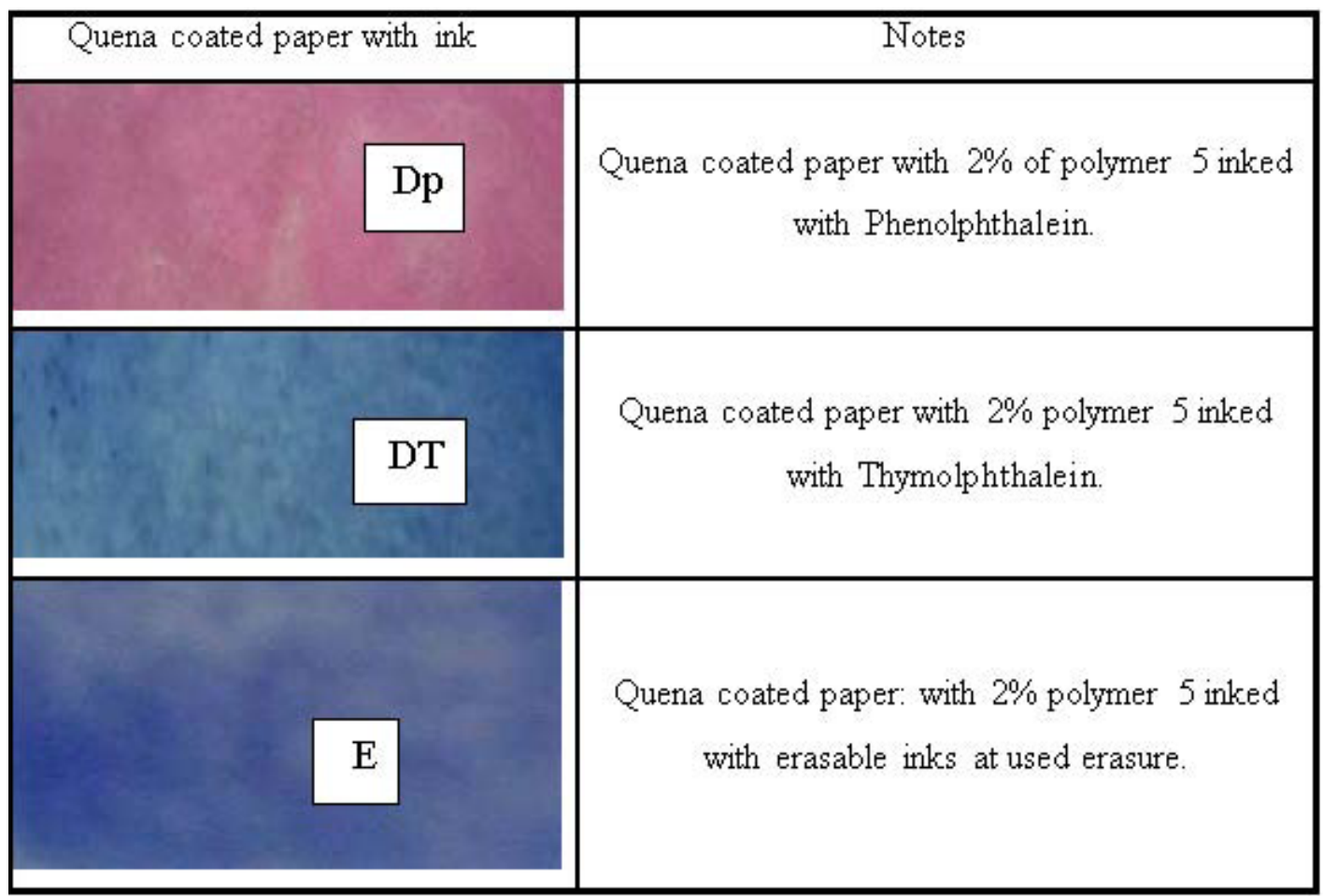

Fig 9. Photomicrographs of coated Quena paper inked polymer 5 with high ink gloss and ink density. 
improvement of the ink stability on the polymer latex-coated paper, and more particularly for disappearing inks if compared with the untreated paper marked with the same ink. The color of disappearing ink decayed after 3 days for untreated paper sample, while it remained for more than 4 months on the polymer latex-coated paper. Similar results were also obtained in case of erasable ink samples. Among the polymer latexes used in this study, the ink gloss and ink density for all inks were enhanced on the paper coated with the polymer latex containing Texapon $\AA P$ surfactants. These promising results contribute in the reduction of use of erasable or disappearing inks in forgery of documents value.

\section{References}

1. El-Molla M. M. and Saeed E.; Fading time study on prepared thymolphthalein, phenolphthalein and their mixture disappearing ink, Research Journal of Textile and Apparel, 9-18(2008).

2. Brunelle R. L. and Reed, R.W.; Forensic Examination of Ink and Paper, Charles. Thomas, Springfield, IL (1985).

3. Valderrama L. and Valderrama, P.; Nondestructive identification of blue pen inks for documentoscopy Purpose using I Phone and digital image analysis including an approach for interval confidence estimation in PLS-DA models validation, Chemometrics and Intelligent Laboratory Systems, 156, 188-195 (2016).

4. Zhu M., Qiao W., Liu H. and Sun Y.; Synthesis of a novel polymerizable surfactant and its application in the emulsion polymerization of vinyl acetate, butyl acrylate, veova 10, and hexafluorobutyl methacrylate, Journal of Applied Polymer Science, 107, 624-628 (2008).

5. Annable T., Brown R. A., Padget J. C. and Van den Elshout A.; Improvements in the application properties of water based low voc coatings, Surface Coating International, 81(7), 321-329 (1998).

6. Chen, Q., Chen G., Tang B. and Tai J.; Study on the printability of coated paper on high-fidelity digital printing, Advances in Printing and Packaging Technologies, 262, 410-413 (2013).

7. Ignk C.; Micro emulsion polymerization of styrene in the presence of anionic emulsifier, Advances in Colloid and Interface Science, 82, 253-273 (1999).

8. Schork U., Poehlein G., Wang S., Reimers J., Rodrigues J. and Samer C.; Mini-emulsion polymerization, Colloids and Surfaces, A: Physiochemical and Engineering Aspects, 153, 3945 (1999).

9. El-Molla M.M., Shama, S.A. and Saeed, S.E. Preparation of disappearing ink and Studying the fading time on different paper surfaces, Journal of Forensic Sciences, 58, 188-194 (2013).

10. El-Sherif H. M., Nasser, A. M., Hussin, A. I., Abd El-Wahab, H., Ghazy M. B. M., and Elsayed A. E., Nano emulsion binders for paper coating synthesis and application. Journal of Macromolecular Science, Part A Pure and Applied Chemistry, 271287 (2017).

\section{ISO 2834-1 (2006).}

12. TAPPI T 480, Om -92 .

13. Morsy F. A. and El-Sherbiny S.; Mechanical properties of coated paper: Influence of coating properties and pigment Blends, Journal of Materials Science, 39(24), 7327-7332 (2004).

14. Wang Y. L., Liu, Y. X., Hu K. X. and Ping, W.; Study on coating pore structure and its influence on print properties of low gloss coated paper, Second International Papermaking and Environment Conference, Proceeding, Books A and B, 901-904 (2008)

15. Forsstrom U., Dickson R. and Gron, J.; Coating coverage and structure of Wood Free paper precoated with the film press. Wochenblatt Fur Papierfabrikation 128(14-15), 985-992 (2000).

16. Kentta E., Lamminmaki, T., Rautkoski, H., Teir, S., Bacher, J., Kettle J. and Sarlin J.; Silica pigment produced from silicate mining side streams for inkjet paper coating application, Nordic Pulp \& Paper Research Journal 28(1), 22-27 (2013).

17. Li Y., Zhang, J., Li, H. S., Gu, W. J. and He, B. G.; Analysis of the Coating surface Properties of Coated Paper, Proceedings of the 2015 International Conference on Materials, Environmental and Biological Engineering, 10, 250-25 (2015).

18. Kajanto I.; Effect of Formation on Print Unevenness. Proceedings of the TAPPI International Paper Physics Conference, Kona, HI, 281-290 (1991).

19. Aydemir C. A study on the printability properties of alkali-sized recycled papers. Science and Engineering of Composite Materials, 23(5), 565571 (2016).

20. Gigac J., Stankovská, M. and Kasajová, M.; 
Interactions between offset papers and liquids. Wood Research, 56(3), 363-370 (2011).

21. Adams J.M.; Particle size and shape effects in materials science: Examples from polymer and paper systems. Clay Minerals, 28, 509-530 (1993).

22. Kasmani J.E., Mahdavi, S., Alizadeh, A., Nemati, M. and Samriha, A; Physical properties and printability characteristics of mechanical printing paper with LWC. Bioreseources 8(3), 3646-3656 (2013).

23. Tripathi P., Joyce, M., Lee, D.I., Fleming, P.D. and Sugihara, M.; Comparison of the surface and print quality of curtain and blade coated papers. Swansea Printing Technology Ltd, TAGA Journal, 3, 203213 (2007).

24. Chinga G. and Helle, T.; Structure characterization of pigment coating layer on paper by scanning electron microscopy and image analysis, Nordic Pulp and Paper Research Journal 17(3), 45-58 (2002).

25. Sood Y. V., Tyagi S., Tyagi R., Pande P. C. and Tandon R.; Effect of base paper characteristics on coated paper quality, Indian Journal of Chemical Technology 17(4), 309-316 (2010).

26. Dahlström C., Allem R. and Uesaka T.; New method for characterizing paper coating structures using argon ion beam milling and field emission scanning electron microscopy; Journal of Microscopy, 241 (2),179-187 (2011).

27. Zhu M., Qiao W., Liu H. and Sun Y.; Synthesis of a novel polymerizable surfactant and its application in the emulsion polymerization of vinyl acetate, butyl acrylate, veova 10, and hexafluorobutyl methacrylate, Journal of Applied Polymer Science, 107, 624-628 (2008).

28. Alain D. and Emmanuelle Marie; Macromolecular surfactants for mini-emulsion polymerization, Advances in Colloid and Interface Science, 150, 90-105 (2009).

(Received 11/7/2018; accepted 16/8/2018)

\section{تطبيق بعض البوليمرات فى منع تزوير المستندات الورقية}

محمد بسيونى مرسى غازى'، وليد خالد الزواوى ‘، علاء الاسوقى السيد” ،طه محمد عبدالله الابس؛، محمد رضوان

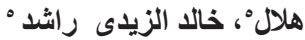

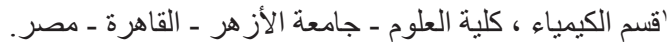

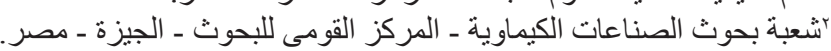

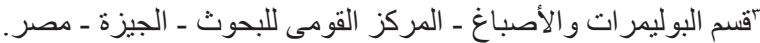

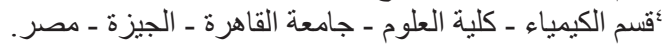

مصلحة الطب الثرعى ـ وزارة العدل ـ القاهرة ـ مصرة.

الههف الرئيسى من هذا البحث هو تحسين قابلية طباعة الأوراق من خلال طلائها بأنو اع مختلفة من البوليمر أثناء

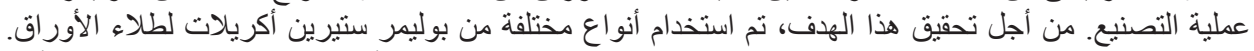

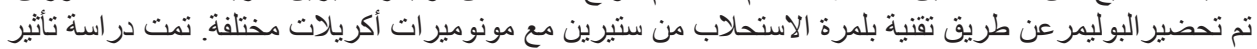

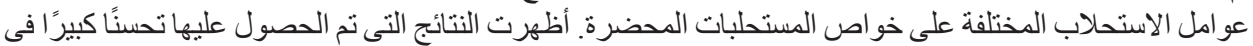

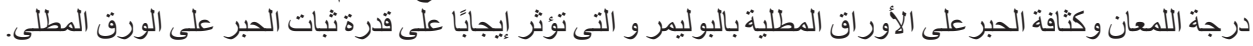

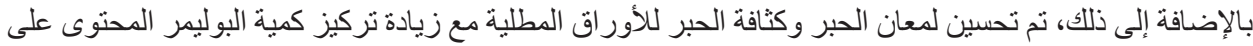

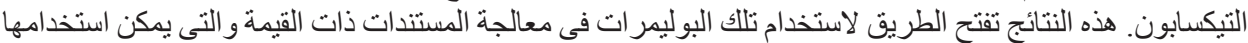

فى تثبيت الأحبار المتاطيرة (القابلة للإختفاء) على لإنى الورق مما يؤدى إلى إمكانية منع التزوير.

Egypt. J. Chem. 62, No. 1 (2019) 